\title{
A centenary of Robert T. Leiper's lasting legacy on schistosomiasis and a COUNTDOWN on control of neglected tropical diseases
}

\author{
J. RUSSELL STOTHARD ${ }^{1} *$, NARCIS B. KABATEREINE ${ }^{2}$, JOHN ARCHER $^{1}$, \\ HAJRI AL-SHEHRI ${ }^{1}$, LOUIS ALBERT TCHUEM-TCHUENTÉ ${ }^{3}$, \\ MARGARE'T GYAPONG ${ }^{4}$ and AMAYA L. BUSTINDUY ${ }^{5}$ \\ ${ }^{1}$ Department of Parasitology, Liverpool School of Tropical Medicine, Liverpool, L3 5QA, UK \\ ${ }^{2}$ Vector Control Division, Ministry of Health, P.O. Box 1661, Kampala, Uganda \\ ${ }^{3}$ Centre for Schistosomiasis and Parasitology, Yaoundé, Cameroon \\ ${ }^{4}$ Dodowa Health Research Center, Ghana Health Service, Dodowa, Ghana \\ ${ }^{5}$ Department of Clinical Research, London School of Hygiene and Tropical Medicine, Keppel Street, London, WC1E \\ $7 H T, U K$
}

(Received 2 February 2016; revised 5 April 2016; accepted 12 April 2016; first published online 1 fuly 2016)

\section{SUMMARY}

Part of Robert T. Leiper's (1881-1969) lasting legacy in medical helminthology is grounded on his pioneering work on schistosomiasis (Bilharzia). Having undertaken many expeditions to the tropics, his fascination with parasite life cycles typically allowed him to devise simple preventive measures that curtailed transmission. Building on his formative work with others in Africa and Asia, and again in Egypt in 1915, he elucidated the life cycles of African schistosomes. His mandate, then commissioned by the British War Office, was to prevent and break transmission of this disease in British troops. This he did by raising standing orders based on simple water hygiene measures. Whilst feasible in military camp settings, today their routine implementation is sadly out of reach for millions of Africans living in poverty. Whilst we celebrate the centenary of Leiper's research we draw attention to some of his lesser known colleagues, then focus on schistosomiasis in Uganda discussing why expanded access to treatment with praziquantel is needed now. Looking to WHO 2020 targets for neglected tropical diseases, we introduce COUNTDOWN, an implementation research consortium funded by DFID, UK, which fosters the scale-up of interventions and confirm the current relevance of Leiper's original research.

Key words: Schistosoma, life cycle, schistosomiasis, R. T. Leiper, Uganda, praziquantel, NTD scorecard.

PATRICK MANSON'S FIRST HELMINTHOLOGIST

There is a long list of eminent parasitologists of Scottish decent active in the 1870-1920 period, who were at the forefront of the great advances made in the battle against parasitic diseases (Barrett et al. 2015; Cox, in press). This period has often been described as 'the golden age of parasitology' and a most prominent figure throughout was undoubtedly Sir Patrick Manson (1844-1922). Manson is widely acknowledged as 'The Father of Tropical Medicine' and was largely responsible for the creation of the London School of Tropical Medicine that opened in 1899 as part of the Seamen's Hospital Society's Branch Hospital at the Albert Dock (Cook, 2007). Under his influence many made significant international contributions, for example Ronald Ross (1878-1937) in protozoology, and in the nascent field of medical helminthology, his first appointee, Robert Thomson Leiper

* Corresponding author. Department of Parasitology, Liverpool School of Tropical Medicine, Liverpool, L3 5QA, UK. Tel: +44 (151) 705-3724. E-mail: Russell. Stothard@1stmed.ac.uk
(1881-1969), was to be particularly productive (Willmott, 1981). Indeed, Leiper was to have an influential role in all aspects of pure and applied helminthology not only within the London School but also much further afield (Grove, 1990).

\section{LEIPER AND THE LONDON SCHOOL}

At the age of 24, Leiper joined the London School in 1905 after graduating from the University of Glasgow in medicine and very quickly gained international prominence whilst on an expedition to Accra, Ghana as Carnegie Research Scholar. While in Ghana, he elucidated the life cycle of the Guinea Worm (Dracunculus medinensis) and devised simple measures for its control, still used today (Grove, 1990). First introduced to schistosomiasis in Egypt by Arthur Looss (1861-1923) between 1906 and 1907, he also took part in the Egyptian Government's helminthological survey of Uganda. It was not until 8 years later and again in Egypt between 1915 and 1916, that he resolved the controversy behind Bilharzia. Second time around, he clearly described the essentials of life cycles of Schistosoma mansoni and 
Schistosoma haematobium, deducing key intervention points. This feat did not come 'out of the blue' for it was firmly based on formative work in the preceding year with E. L. Atkinson (1881-1929) in China, and guided by Japanese researchers who shared with him their knowledge of the life cycle of Schistosoma japonicum (see below). Other pioneering and seminal studies were conducted during 1912-1913 in Southern Nigeria where he incriminated Tabanid flies of the genus Chrysops as vectors of loiasis, as initially suggested by Manson (Grove, 1990).

Shortly before Manson's death, in 1918 Leiper was appointed to the Courtauld Chair in Helminthology, a post subsequently held by J. J. C. Buckley (19041972) and then by G. S. Nelson (1923-2008). Buckley and Nelson each had a tremendous influence on the study of parasitology, which built on Leiper's legacy with newer research methods and grounded on meticulous and painstaking observation(s). In 1923, and in the same year that Leiper was elected a Fellow of the Royal Society, he founded the Fournal of Helminthology, which continues to this day. He remained its lead editor until 1946 and, by raising substantial funds, Leiper was instrumental in establishing at Keppel Street the new London School of Hygiene \& Tropical Medicine, which opened in 1929 (Fig. 1).

\section{HIS RETIREMENT AND LASTING INFLUENCE}

Leiper's association with the London School was very enduring, working there until his retirement in 1947. He still remained active afterwards continuing to work up to 1958 , then aged 77 , as the Director of the Commonwealth Bureau of Helminthology at St. Albans, Hertfordshire, UK which became later incorporated into the Centre for Agriculture and Biosciences International (CABI). The Bureau had previously evolved from the Imperial Bureau of Agricultural Parasitology and was originally part of the Winches Farm Estate, which Leiper himself had helped the London School to purchase in 1924 (Willmott, 1981). The Winches Farm Research Station was later revitalized by Nelson and directed by G. Webbe (1929-1999) until its closure in 1992.

From 1958 and even in 'full-retirement', Leiper still influenced parasitology. As he had a passion for farming, like his father before, he was given a pedigree cow upon retirement from the London School. He continued to enjoy agriculture keeping abreast of new practices in animal husbandry. It was said that a peaceful home life had given him a happy base to secure his endeavours; 3 years after joining the London School, he married Ceinwen Saron Jones, a dentist practicing in Liverpool. They had three children, a son and two daughters, and remained married for 58 years until her death in 1966. At the time of his death in the early hours of 21st May 1969, Leiper owned three farms, two in Scotland and one in Hertfordshire.

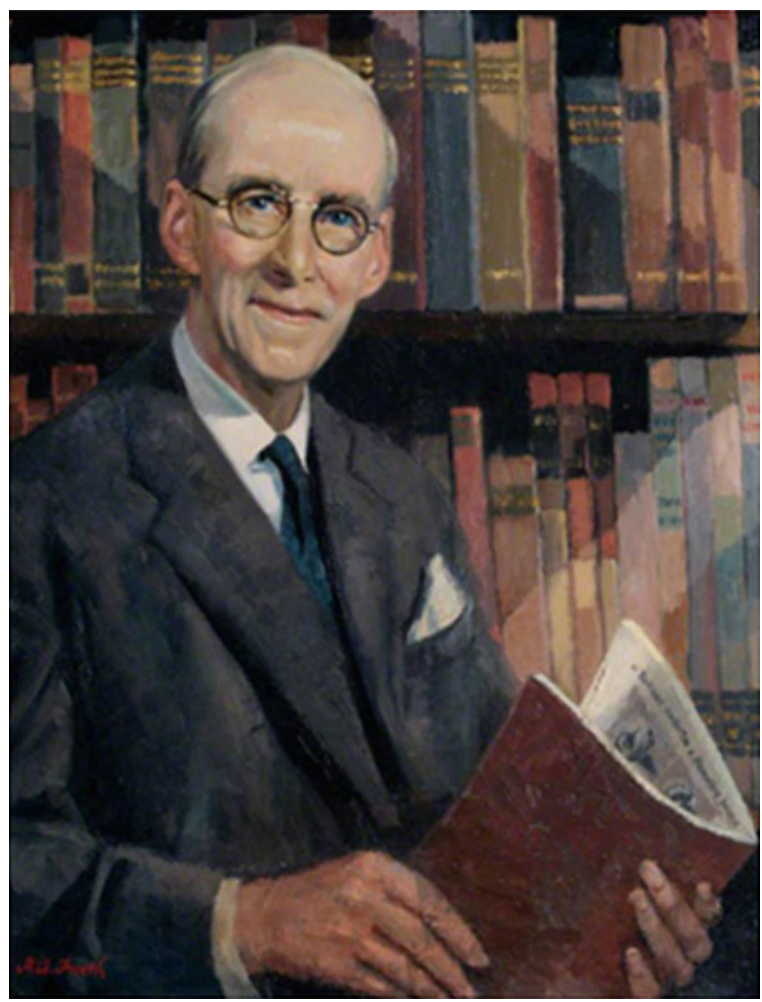

Fig. 1. As commissioned upon his 80th birthday, a portrait in oils of Professor R.T. Leiper by Andrew Freeth (Royal Society of Portrait Painters) has been on display in the London School of Hygiene and Tropical Medicine since 1972. There are two rather subtle points to note. First, as Leiper was a chain-smoker his habitual cigarette in his right hand was later removed so as not to offend antismoking campaigns. Second, the untitled booklet in his hands clearly has images of Bulinus and Biomphalaria, the freshwater snails involved in transmission of Schistosoma spp.. Despite being the world's eminent helminthologist, he seems happy to be remembered for these two things, a smoker and a pioneer of medical malacology, perhaps a testament to his mischievous humour.

A good example of his exceptional influence on parasitology can be found in the festschrift in honour of his 80th birthday in 1961 in the Fournal of Helminthology. In the preface, there is a long list of signatures from very distinguished attendees, including from H.A. Baylis (1889-1972) Head of Parasitic Worms at the British Museum (Natural History). This was no small testament to the respect he commanded even in those he may have once unsettled (see below). His longstanding colleague at the London School P.C.C. Garnham (1901-1994) described him "He has a very decisive manner of speech and is a good lecturer. Those who argue with him or come to cross purposes usually get the worst of the argument. He is not to be deviated from his course" (Garnham, 1970). Other insights from P. Manson-Bahr (1891-1966), Sir Patrick Manson's son-in-law, include "He is kind, charming and helpful to the worthy, but withering to the insincere 


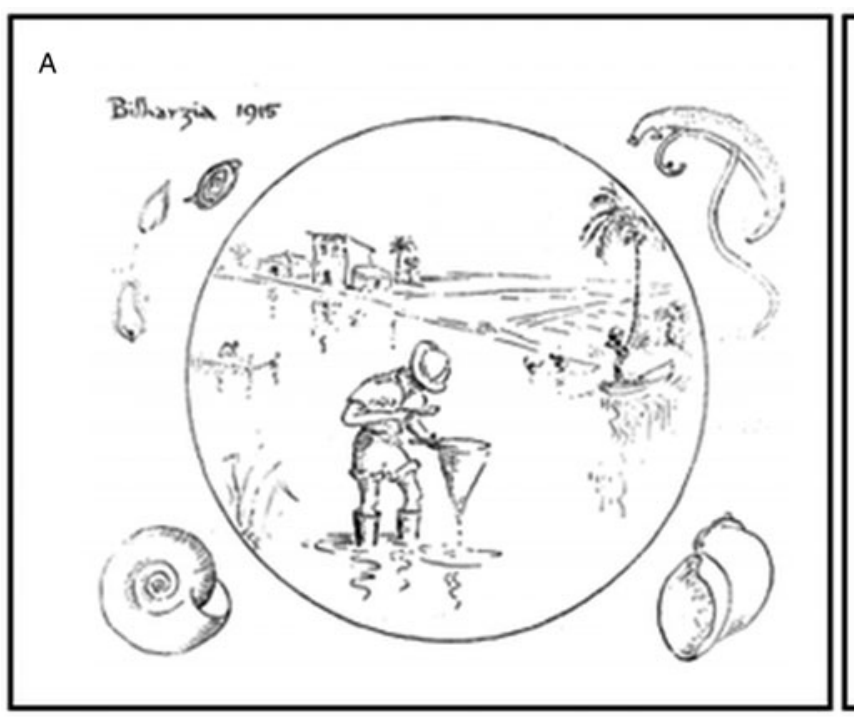

B

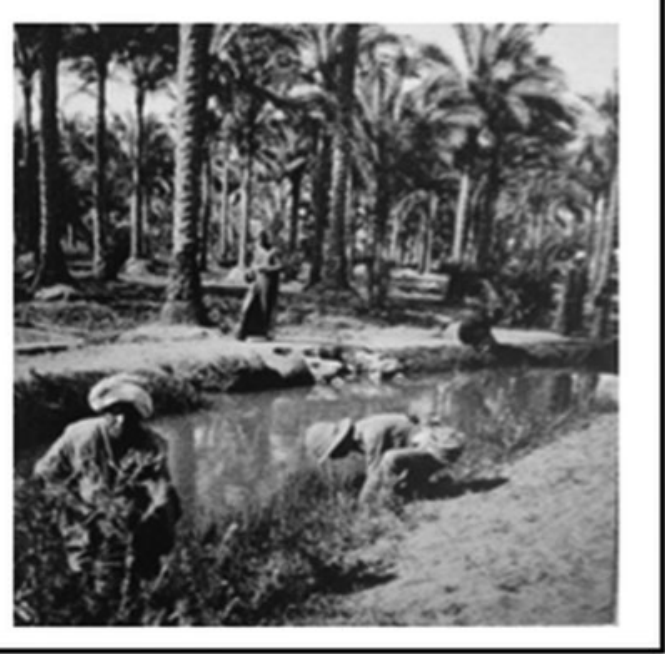

Fig. 2. In celebration of Leiper's work on schistosomiasis. (A) Cartoon sketch by Joy Gordon of his 1915 work in Egypt as part of his 1961 festscrift in Fournal of Helminthology. (B) Black and White photograph of Leiper's collectors working in the small irrigation canals in Egypt foraging for snails where one might infer how arduous field-collecting can be in the midday sun.

or make-believe" (Manson-Bahr, 1961). A former student who was later Reader in Medical Helminthology at the London School, Philippus L. LeRoux (1897-1962) commented "he has contributed much, by training and encouraging helminthologists, to alleviate pain, miseries, losses and mortality from helminthiasis in man and man's domesticated animals" (LeRoux, 1961). In the context of today's OneHealth, Leiper should be recognized as a seminal pioneer exploring these concepts.

Leiper maintained regular contact with the London School until shortly before his death. In life he had obtained numerous awards including the Mary Kingsley Medal of the Liverpool School of Tropical Medicine and the Bernhard Nocht Medal from the Tropeninstitut in Hamburg, Companionship of the Order of Saint Michael and Saint George (CMG) and an Honorary LLD from the University of Glasgow and had more than 180 scientific papers to his credit, the vast majority as senior or sole author (Nelson, 1977) (Fig. 2).

\section{LEIPER'S EARLY CAREER}

Aged 24 and writing from Glasgow, on 28th December 1904 Leiper submitted his application to the London School of Tropical Medicine with testominals from R. Stockman (1861-1946), Robert Muir (1864-1959) and J. F. Gemmill (1867-1926). By his own admission he was more interested in the biological side of medicine and had taken full advantage of facilities at the Marine Biological Station at Millport, on the Isle of Cumbrae in Scotland. There he had pursued the study of parasitic worms, notwithstanding being the honorary librarian. Even as a keen student, he was particularly productive. He published his first paper in 1902 in Nature, a description of a parasitic flatworm (Avagina unicolor) found in the accessory canal of a sea-urchin. In his application, he was especially proud to report that as a Carnegie Medical Research Scholar and University Research Student in Embryology, he had been entrusted to conduct the examination of various trematodes, turbellarians and polychaetes brought back from the Scottish National Antarctic Expedition (SNAE) 1902-1904. The SNAE was led by W. S. Bruce (1867-1921) but was largely overshadowed by the concurrent Discovery Expedition 1901-1904 led R. F. Scott (1868-1912). By another helminthological twist of fate, the lives of Leiper and Scott were to be later intertwined with the lives of two others.

It was a good choice, perhaps, to have Stockman, Muir and Gemmill as referees and while Muir and Gemmill took much pleasure in their appraisals of him, Stockman commented "I can testify from personal knowledge that he is a competent clinician and pathologist. He has, however, devoted his time and energies chiefly to the study of Zoology and Embryology, and more particularly to the morphology and lifehistory of worms". This might be lukewarm praise to some but to Manson it must have been just the ticket to appoint an ambitious, resourceful young man. On a more personal note, Leiper was reluctant to pursue a career in clinical medicine (Willmott, 1981). This was forged by the unhappy memory of his late father who had long suffered and died with tuberculosis which, at that time, had little in the way of prevention yet alone cure.

\section{LEIPER'S FIRST EXPEDITIONS AND} ACHIEVEMENTS

Whilst at the London School, Leiper did not disappoint. As teaching was delivered in discrete subject 
blocks there was ample time for travels abroad. Visiting the Gold Coast in 1905, he conducted experimental infections of primates to show how ingestion of infected Cyclops, the water flea harbouring Dracunculus medinensis, led to dracunculiasis and the transmission of Guinea Worm (Grove, 1990). After proving this, he devised basic measures of prevention involving simple filtration of drinking water through cotton gauze. Largely as a result of this measure, Guinea Worm is now on the verge of eradication albeit new concerns of zoonotic transmission in Chad within a hitherto unknown infection reservoir in dogs (Callaway, 2016). Typical of Leiper he was often prophetic, in 1910 for example, he wrote a seminal paper discussing the role of domesticated animals in dracunculiasis transmission concluding that domestic dogs and horses were permissive hosts (Leiper, 1910).

In 1906 Leiper made his first visit to Egypt and performed studies on parasites, including schistosomes, in the Cairo School of Medicine within the laboratory of the eminent parasitologist Arthur Looss. It is worthy to note that in his later 1915 return, Leiper's ensconced himself within Looss's vacant laboratory, for Looss being German had to vacate Cairo at the start of WWI (Nelson, 1977). Whilst schistosomiasis was formally described decades before by T. M. Bilharz (1825-1862), the disease was firmly engrained in Egypt and had no known cure (Grove, 1990). Moreover, its transmission was enigmatic and particularly puzzling and controversy raged concerning the significance of lateral and terminal spined eggs and how miracidia, the ciliated larval stage released from eggs, either infected people directly or was indirectly transmitted by an intermediate host (Farley, 1991). Both opinions were complete conjecture but the latter would imply additional larval stages of unknown form and function (Cook, 2007). Leiper's studies with Looss were inconclusive but they no doubt focused his mind on this biological conundrum, likely whetting his ambition to be the only man to solve it. There were of course several others pursuing similar investigations, such as the Brazilian M. A. Parajá da Silva (1873-1961) who had hotly debated the 'second species' with Looss and with whom he and Manson were in correspondence with (Katz, 2008).

The following year Leiper had a more productive time as medical officer for the Egyptian Government Railway Survey operating between Lake Victoria and Lake Albert Uganda. There he was employed to look after the health of the survey teams but was much more interested in parasites of wildlife, finding a new species of liver fluke, Fasciola nyanzae, Leiper 1910, in a hippopotamus near Murchison Falls. He collected and described various other helminthological curiosities from elephants, on return to Egypt by way of the Nile.

Subsequently he fostered his interests in parasites in wildlife but now at home in the UK, where he was helminthologist to the Grouse Diseases Enquiry Committee (GDEC). Since the turn of the century there had been several mass die-offs of grouse, and other game birds, of sufficient calamity to warrant a national intensive investigation of its aetiology (Campbell, 1988). To this end, Leiper worked with E. A. Wilson (1872-1912) who was the field observer for the GDEC. Wilson was a medical doctor as well as a very talented natural historian and illustrator. Several years earlier, Wilson had accompanied Scott on the Discovery Expedition and was to continue with this strong Antarctic association in years to come. Concerning the epizooty in grouse, Wilson and Leiper were able to show, by experimental infections, that the nematode Trichostrongylus pergracilis was responsible for the periodic decimations (Nelson, 1977; Campbell, 1988).

ANTARCTIC PARASITES AND ASIAN SCHISTOSOMIASIS

Perhaps it was fate that Leiper would again study Antarctic parasites for Wilson was requested by Scott to act as his Chief Scientific Officer for the British Antarctic Expedition (BAE) 1910-1913. The BAE was informally known as the Terra Nova Expedition after the name of their ship, a coal-fired steam whaler. Woefully, both Scott and Wilson were to later perish, along with three others, on their ill-fated march to the South Pole. Once the details of their heroism became widely known, their demise was to subsequently inspire a tremendous future heritage of scientific exploration (Campbell, 1988).

A significant member of Scott's Terra Nova team was the Navy Surgeon E. L. Atkinson (1881-1929). Although younger than Leiper, only by several months, he and Leiper were known to have completely different and ill-fitting demeanours. 'Atch' as he was affectionately known by BAE staff, was employed both as expedition medical officer and parasitologist. It is outside the scope of this paper to describe Atkinson's unique talents, having been done admirably before (Nelson, 1977; Campbell, 1988), but suffice to say that after Scott's failure to return, he held the BAE together with remarkable fortitude and courage.

The BAE was foremost a scientific endeavour and thus Atkinson subsequently worked with Leiper at the London School to characterize the parasitic helminths he had collected, which resulted in an outstanding academic monograph recording 38 species (Leiper and Atkinson, 1915a). Many of these species were novel and named in honour of their BAE colleagues (and their wives) (Campbell, 1988; Campbell and Overstreet, 1994). The history and associations with these names is particularly interesting and been previously discussed by William C. Campbell (the 2015 Nobel Laureate) and Robin M. Overstreet (Campbell and Overstreet, 1994). 

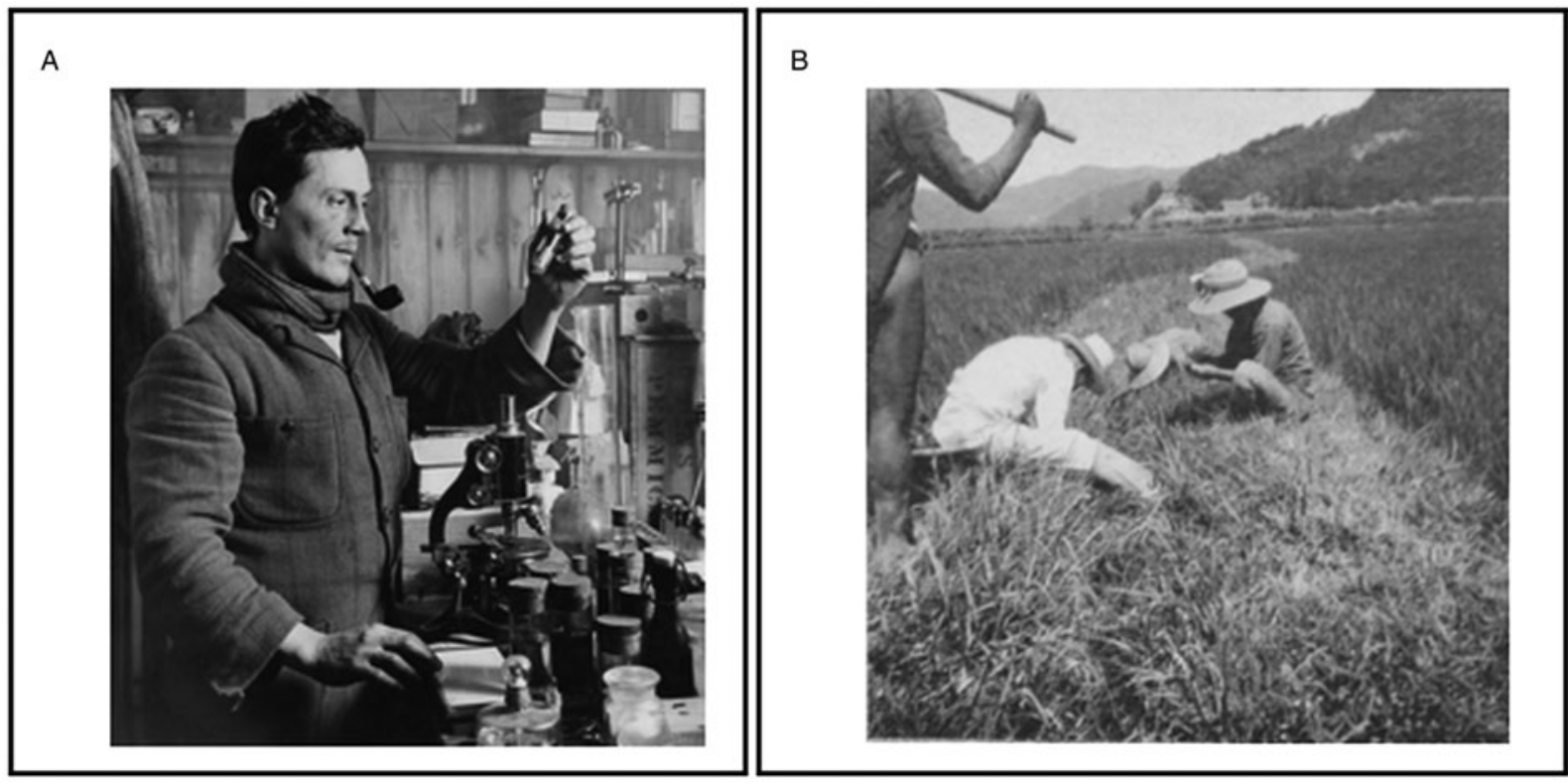

Fig. 3. Leiper's initial studies on Asian schistosomiasis with Atkinson. (A) Black and White photograph of Edward Atkinson in 1911 taken by Herbert Ponting (1870-1935) during his research on the Terra Nova expedition. Atkinson had recently suffered severe frost-bite on his hands and face, the remnants can be seen by his cheek scars and swollen right index finger. Upon his return to the UK, he worked with Leiper on his collection of parasitic worms from the Antarctic. (B) Black and White photograph of snail collecting in China along the marshes surrounding rice paddies.

For example, unbeknownst to them the nematode Terranova antarctica, Leiper and Atkinson, which Atkinson had encountered from a gummy shark, was later shown to be a significant cause of anisakiasis in Japan (Campbell, 1988).

Although researching the parasitology of fishes the puzzle of Bilharzia was still in Leiper's mind as it was with other influential people at that time, such as Lord Horatio Kitchner (1850-1916), the British Administrator in Egypt. Lord Kitchner was to later put it "It was high time that serious steps should be taken to prevent the continuity of infection that has been going on so long in the country". Bilharzia was also known to occur in China where it was a considerable problem within the British Navy, oddly enough in officers and not ordinary seamen, on their gunboats patrolling the Yangtze River (Hamilton Fairley, 1951). By obtaining a grant from the Colonial Office through its Tropical Diseases Research Fund, Leiper and Atkinson were able to proceed to the Far East and investigate the mode of spread of Bilharziasis and, if possible, collect experimental evidence on this subject (Atkinson, 1916).

What subsequently happened on this expedition to China and Japan is best told by George Nelson for he considers Leiper and Atkinson's (1915b) publication entitled "Observations on the spread of Asiatic schistosomiasis" a milestone in helminthology (Leiper and Atkinson, 1915b); never in the whole history of parasitology have two men of such contrasting backgrounds and personalities collaborated to produce a paper that attracted so much attention (Nelson, 1977). In essence their time in the field did not go well and after suffering the company of Leiper, Atkinson who incidentally was once a champion boxer in the Navy, wanted to "...give him (Leiper) a sound thrashing and tell him what he is for the good of his soul and then leave him" for Leiper had typically everyone "by-the-ears" (Goodwin, 1996). The poignancy should be measured by the gravity of which Atkinson had suffered in the Antarctic and was likely exhausted by always having to clear things up.

On a more positive note, they were able to follow the life cycle of $S$. japonicum linking miracidia to intermediate host (the snail Katayama nosophora), the internal sporocyst stages then to cercariae. It is this highly motile larvae stage, which is shed by snails into water and has a radically different morphology to miracidia, which is the infectious form to humans (Leiper and Atkinson, 1915b). Thus it was the cercaria, not the miracidium, which was able to infect mammals by per-cutaneous transmission, or to cross the oral mucosa, which then went onto mature as an adult worm (male or female) within the bloodstream. Notably, they were only able to conduct these observations after Leiper made two short visits to Japan to seek advice from A. Fujinama (1870-1934). It was Fujinama who alerted him to the significant steps Japanese co-workers had already undertaken in elucidating the life cycle of $S$. japonicum publishing their work in Japanese journals (Goodwin, 1996). These reports were largely outside the notice of the English speaking world (Tanaka and Tsuji, 1997) and being clearly scooped, Leiper was understandably irate (Fig. 3). 


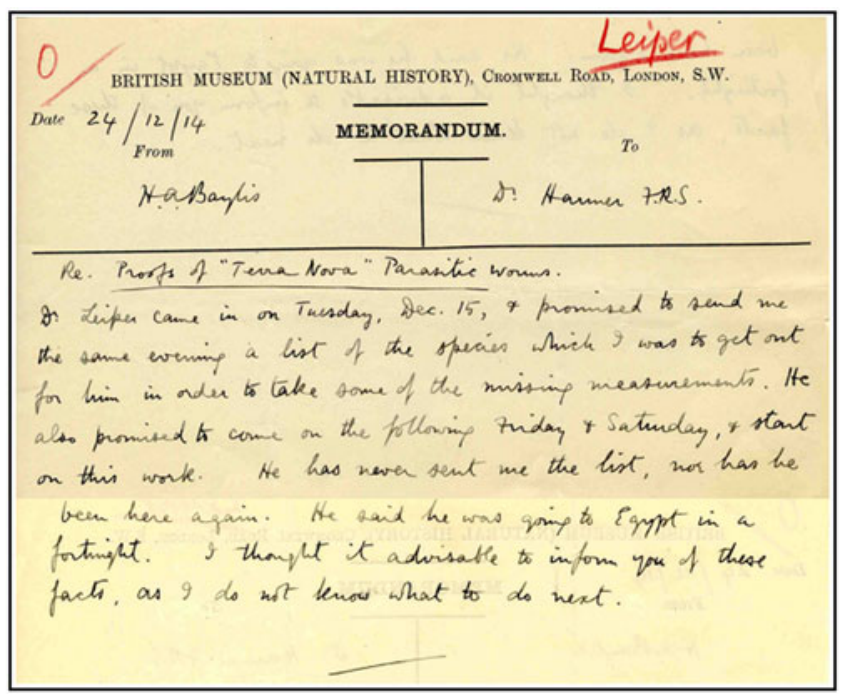

Fig. 4. Leiper unsettles Harold Baylis, for it was exceptional practice for British Museum (Natural History) staff to work on Saturdays. This note from Baylis to S.F. Harmer RFS (1862-1950) the Keeper of Zoology at the B.M.(N.H.) clearly shows how active Leiper could be pushing ahead the Terra Nova manuscript and how on Christmas Eve 1914 and Baylis was worried about the fuss Leiper might create if unsatisfied. Nevertheless, nearly half a century later Baylis was happy to sign Leiper's festscrift.

\section{AGAIN IN EGYPT AND ON A BREVET COMMISSION}

With the outbreak of the first World War in 1914 and returning from China, Atkinson and Leiper went their separate ways with little further interactions; Atkinson to Gallipoli and later the Western Front while Leiper went again to Egypt. However, Leiper was now armed with knowledge of the S. japonicum life cycle. To fund his trip, The British War Office was immediately receptive to Leiper's application to resource this trip and appointed him as brevet Lieutenant-Colonel in the Royal Army Medical Corps to "Investigate Bilharzia disease in that country and advise as to the preventive measures to be adopted in connection with the troops". As an aside, a good example of his diligence and the Leiper-effect on others is evidenced by his visit to the British Museum (Natural History). Before leaving for Egypt, he needed to seek confirmation of certain measurements of the Antarctic worms before their corrected monograph proof could be published. This was very much to the consternation of Baylis who was also very clearly had 'by-the-ears' (Fig. 4).

On this mission to Egypt Leiper, as Wandsworth Scholar, was accompanied by two other London School staff, J. G. Thompson (1878-1937), who was given a captaincy, and the London School's administrator R. P. Cockin (1889-1918). They arrived in Egypt on 8th February 1915 but soon encountered problems. These were reported back to Ronald Ross at the London School by Leiper who later wrote "Within a week of our arrival Dr Cockin had fallen sick and was invalided home. Three weeks earlier I had been admitted to hospital with scarlet fever. It was not until the beginning of April foregoing my convalescence, I was able to start field investigations at Marg. Early in May the opening of the Gallipoli campaign, with its rush of wounded and the attendant excitement in Cairo, brought pressing local suggestions for foreclosing of my mission".

Thus nearly all of the early snail collecting therefore had fallen on the shoulders of Thompson who also wrote back to Ross saying that looking for snails in the canals and ponds "...was very exhausting work here in the sun especially travelling distances to search but it is extremely interesting". Nonetheless, they were advantaged to focus on those snails that shed cercariae with characteristic bifurcate tails. Furthermore, with these cercariae it was possible to establish experimental infections in laboratory rodents and to follow the maturation of schistosomes within the vasculature system. Using the ova shed from these animals allowed experimental challenge and infection of laboratory-bred freshwater snails in order to identify clearly, which species were and were not permissive hosts (Cook, 2007). Without doubt their progress was rapid and once sufficient field and experimental evidence had been accrued, Leiper left Egypt on 15th July 1915 to return to the London School. There he assembled all the information, and authored a clutch of sequential papers in the Fournal of the Royal Army Medical Corps, which forms the backbone to our understanding of schistosomiasis today (Cook, 2007).

\section{ADOPTING SIMPLE MEASURES OF PREVENTION} AND CONTROL

To his credit, Leiper had clarified beyond doubt that there were two species of African schistosome, $S$. haematobium and S. mansoni (Farley, 1991). Each 
could now be clearly recognized by their characteristic egg-spine morphology in the excreta of infected hosts, which could also denote co-infection correcting Bilharz's original oversight. Although the species shared many commonalities in their life cycle, crucially they were each restricted in their development in Bulinus and Biomphalaria, respectively. This detail had much broader significance for the endemic zone of each species of schistosome was firmly tied to the distribution of their permissive snail host. Furthermore, from a public health perspective, destruction or removal of these intermediate hosts from the waterways could form an environmental intervention strategy of tremendous importance both in Egypt and China (Jordan, 2000). His seminal study also helped to develop a new field of medical malacology with key scientists such as C. A. Wright (1928-1983), G. D. MandahlBarth (1910-1994) and D. S. Brown (1935-2004) describing even greater complexities in the snailschistosome relationship than he could have ever imagined (Lockyer et al. 2004).

From a military perspective, knowing the life cycle and experimenting with ways to render water safe, Leiper made a variety of significant observations upon which camp standing orders were raised (Farley, 1991). Adhering to these would ensure that troops would not be infected. Like his work on Guinea Worm, the water hygiene measures were based upon simple filtration, boiling water and use of disinfectants. Most importantly, knowing that cercariae are an ephemeral, shortlived larval stage, resting water for at least $24 \mathrm{~h}$ was sufficient to make it safe for bathing. These measures could be implemented without need for expensive equipment; all that was required was a little behavioural change prohibiting troops to swim or bathe in environmental water or to introduce simple hygiene measures when freshly drawn water was to be used (Farley, 1991). Brilliantly, all that was needed to control schistosomiasis was to introduce a modicum of patience along with adequate temporary water storage.

With better knowledge of the life cycle and features of transmission the early clinical significance of the disease in soldiers could be more accurately described. For example, the eminent military physician Sir Neil Hamilton Fairley (1891-1966) helped to develop diagnostic tests based on complement fixation and later pioneered individual treatment with tartar emetic. Like the discovery of the life cycle, the first clinician to use intravenous tartar emetic successfully as an anti-schistosomal drug is controversial, ascribed in the UK to J. E. R. McDonagh (1881-1965) or in Egypt to J. B. Chistopherson (1868-1955). Nonetheless with Manson-Bahr, Fairley confirmed Leiper's experimental observations in rodents but now repeated in monkeys and his new descriptive pathology helped to shed fresh light on symptoms including: fever, urticarial, abdominal pain, enlargement of the spleen and liver, emaciation, bronchitis and diarrhoea (Hamilton Fairley, 1951). From then on, the burden and fear within the British Army of schistosomiasis was greatly diminished (Farley, 1991).

In local communities, however, schistosomiasis continued to flourish although future outbreaks within military settings did occur. An influential outbreak of acute schistosomiasis, or Katayama fever, in tens of thousands of the People's Liberation Army took place in 1949. By incapacitation, the Chinese amphibious assault on Taiwan (Formosa) was delayed sufficiently long enough to allow the US Seventh Fleet enter the Strait of Formosa and abort the communist takeover (Hotez, 2013). This made a deep impression on Chairman Mao, galvanizing a need to eliminate this disease in China. Despite a suite of interventions beginning in 1955, schistosomiasis has proven difficult to eliminate owing to its continued persistence involving zoonotic reservoirs (Zou and Ruan, 2015), as Leiper knew well (Nelson, 1990).

In 1951 Hamilton Fairley commented on the occurrence of schistosomiasis during WWII in Allied Forces when more than 1500 American Officers and 174 army personnel from the Royal Australian Air Force contracted $S$. japonicum. In his Presidential Address to the Royal Society of Tropical Medicine at Portland Place, London, and by all odds Leiper would have been in attendance, Hamilton Fairley surmised that it has taken another world war to make evident the difficulty of finding ova in the feces in mild and atypical schistosome infections and that the extent of subclinical army cases was still unknown (Hamilton Fairley, 1951). More broadly, this summation is very relevant today. There is still a dearth of sensitive diagnostics, which has largely downplayed the clinical significance of disease, especially in children and women, when eggs are seemingly absent in the excreta (Stothard et al. 2014b).

\section{SCHISTOSOMIASIS IN UGANDA TODAY}

Perhaps Leiper would have been interested to learn how in areas where he once worked, in Uganda with the Egyptian Government Railway Survey, the disease is still causing havoc. On the Lake Albert shoreline, Butiaba and Pakwach, once essential ferry ports linking rail and road systems, are hyper-endemic foci for intestinal schistosomiasis. Since Leiper's visit, Butiaba and Pakwach have been the locations of numerous clinical epidemiological surveys for intestinal schistosomiasis (Nelson, 1958; Ongom and Bradley, 1972; Kabatereine et al. 1992, 1996). Throughout this time efforts to control the disease have evolved being contingent with the changing emphasis of 

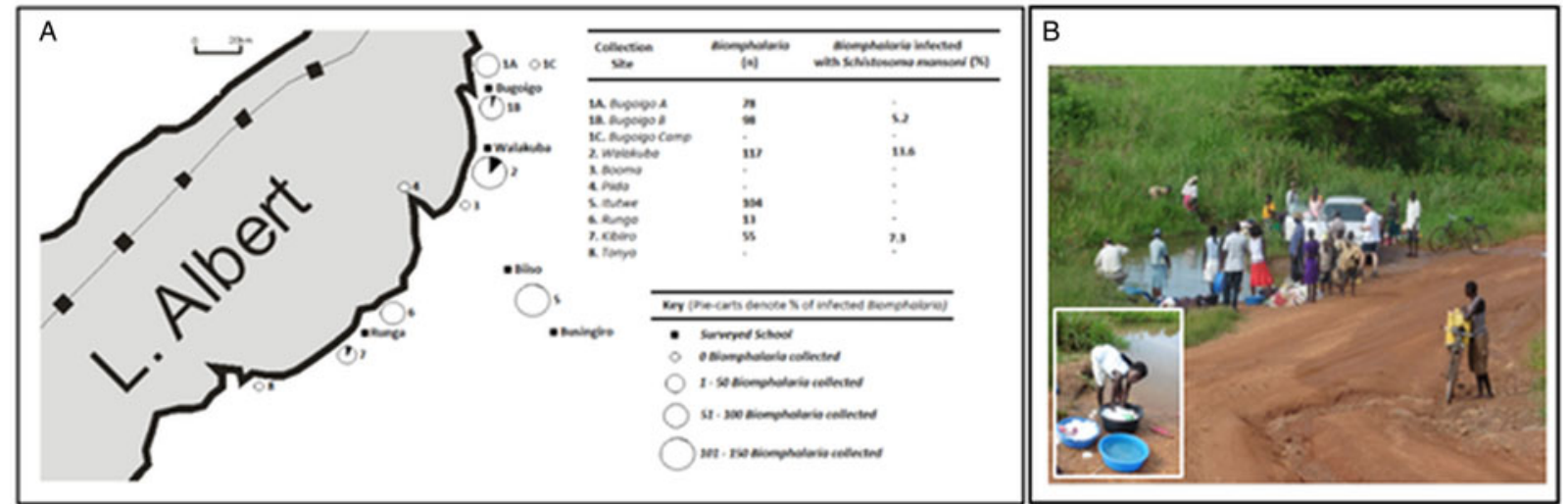

Fig. 5. Malacological and parasitological studies in Uganda on the Lake Albert shoreline. (A) Sketch map of 10 collection points for Biomphalaria and associated location of 5 primary schools (Bugoigo, Walakuba, Runga, Biiso \& Busingiro) examined for intestinal schistosomiasis in May 2015. Whilst Pakwach is located at the northern end of Lake Albert, the settlement of Butiaba occupies much of the peninsula indicated at snail collection site 4 . The table denotes the number of snails collected and occurrence of snails shedding S. mansoni. (B) Ongoing water contact, contradictory to Leiper's advice, such as collecting water in yellow plastic jerry cans and washing clothes [inset] at Itutwe is still a common occurrence along the Lake Albert shoreline. While Bulinus and Lymnaea have been regularly collected from Itutwe since 2002, it was not until May 2015 that Biomphalaria has been encountered making this a possible transmission site away from the lakeshore and in need of further surveillance.

global strategies chiefly guided by the WHO and with available resources from international and national donors and agencies (Loewenberg, 2014). With the drive towards mass drug administration with praziquantel, the National Control Programme (NCP) for Control of Bilharzia and Intestinal Worms was launched in Pakwach in 2003 (Fenwick et al. 2009). The main intention of the NCP was to distribute and administer praziquantel annually to all children attending Universal Primary Education (UPE) schools in endemic areas (Stothard et al. $2014 a$ ). At that time, Uganda was the first country to benefit from the support of the Schistosomiasis Control Initiative, using funds from the Bill \& Melinda Gates Foundation, which purchased and donated praziquantel to the Ugandan Ministry of Health with its Vector Control Division as the lead agency overseeing the programme within country (Fenwick et al. 2009; Fleming et al. 2009). The programme was also seminal for it helped to spearhead a new appraisal of this disease within this country by starting baseline surveys in 2002 with annual followups that recorded a variety of disease-specific information and associated changes with treatment (Kabatereine et al. 2007).

Since 2002, there has been a rich variety of research studies undertaken on the shoreline of Lake Albert and Victoria, inclusive of socio-demographic studies (Dunne et al. 2006; de Moira et al. 2011; Stothard et al. 2011) and medical malacology (Jorgensen et al. 2007; Adriko et al. 2013; Levitz et al. 2013; Rowel et al.2015). Collectively it is clear that control of schistosomiasis in these lacustrine environments is particularly challenging. Today, intestinal schistosomiasis is very firmly engrained in school-aged children, as well as pre-school children and the more obvious high-risk occupational groups such as adult fisherfolk (Seto et al. 2012). Domestic water supplies are typically contaminated with schistosome cercariae contributing to the failure of any viable alternative long term. This freshly drawn water is daily collected from the lake itself and used by all household members in their daily chores and ablutions, oblivious or contravening Leiper's advice (Stothard et al. 2011; Seto et al. 2012).

With the increasing availability of donated praziquantel and the international drive towards reaching WHO 2020 targets, such as sustained treatment coverage of $75 \%$ in school-aged children, there is an expectation that schistosomiasis will significantly decline (Stothard et al. 2014a; Savioli et al. 2015). Our recent parasitological survey of school children across 5 primary schools in Buliisa and Hoima (Fig. 5), has little to foster such optimism. The fecal egg-patent prevalence and arithmetic mean intensity (eggs per gram [epg]) of intestinal schistosomiasis in three primary schools Runga, Walakuba and Biiso in 2003 was: $95 \cdot 2 \%$ (631 epg); $90 \cdot 4 \%$ (1026 epg) and $17 \cdot 2 \% 52$ (epg) while in 2015 was: $86 \cdot 7 \%$ (1723 epg); $80 \cdot 3 \%$ (814 epg) and $19 \cdot 6 \%$ 198 (epg). Despite best efforts after a decade of control with school-based delivery of praziquantel treatment, there has been an intangible decline in egg-patent prevalence or intensity. Moreover, there are still many children with very heavy infections (>3000 epg). As treatment with praziquantel does not guard against reinfection, this is firm evidence that annual administration is insufficient and that short treatment cycles, given out twice or even three times a year, are needed.

We are also still far from having a complete understanding of its full spectrum of morbidity and the 
consequences of associated vascular remodelling (Andrade, 2008). For example, in those with advancing hepatosplenic disease, progressive fibrotic sequelae in other organs and abdominal hypertension can occur and was recently discussed in connection with right ventricular endomyocardial fibrosis detected in a child at Walakuba (Bustinduy et al. 2014). This simply points towards the need for better clinical surveillance of the disease, in all its manifestations, at the periphery of primary health care else we will continue to observe only the tip of the iceberg (Stothard et al. 2014b). A potential solution is to expand access and administration of praziquantel to children younger than school-age who are currently not targeted for treatment. This is very firmly in line with the ethos of preventive chemotherapy, which aims to avert or stall the development of any morbidity but in the pre-school setting there are several impediments and bottlenecks to consider (Stothard et al. 2014a). Only time will tell if this key treatment gap will be sufficiently rectified when an appropriate paediatric formulation of the drug is developed and deployed (Stothard et al. 2013).

\section{INTRODUCING COUNTDOWN}

The practical translation of many of Leiper's findings into tangible improvements in the health of neglected and impoverished populations of the world has been a long time coming (WHO, 2013). Effective control of schistosomiasis in sub-Saharan Africa is problematic and challenging (Southgate et al. 2005; Rollinson, 2009; Rollinson et al. 2013). It clearly exposes several weaknesses in the health system as well as many deficits in our ability to respond comprehensively (Southgate et al. 2005; WHO, 2015). The global response is being tracked as best possible by the neglected tropical disease score card, which seeks to measure progress in commitments and pledges made at the London Declaration on Tropical Diseases (WHO, 2015). Currently the score card places progress on schistosomiasis in red (see http://unitingtocombatntds. org/). Why is this? Put simply, the scale-up of access to praziquantel treatment has been much slower than expected. Currently those that are living in need of treatment are simply not receiving it and those that have access to treatment sometimes refuse to take it in fear of complications or sideeffects for they have an incomplete understanding and awareness of the benefit of treatment (Parker et al. 2008; Parker and Allen, 2011). There have been insufficient biosocial science studies undertaken to rectify this problem and enhance and sustain the performance of NCPs (Allen and Parker, 2011; Rollinson et al. 2013).

Addressing these deficits and needs requires implementation research that is able to provide evidence to expand, strengthen and sustain the delivery of treatment alongside complementary efforts that foster interventions against well-known attack points in the schistosome life cycle (Southgate et al. 2005; Rollinson et al. 2013). Traditionally this needs effective intersectoral dialogue and coordination of resources between, amongst others, the Ministries of Health, Education, Sanitation, Agriculture and Hydroelectricity (WHO, 2013). Responding to this need a 5-year implementation research consortium entitled COUNTDOWN was formed in November 2014 and funded by DFID, UK. The rationale of COUNTDOWN was to conduct research that would attempt to identify and alleviate bottlenecks in interventions and accelerate progress towards WHO 2020 targets for those neglected tropical diseases amenable to preventive chemotherapy (i.e. trachoma, lymphatic filariasis, onchocerciasis, soil-transmitted helminthiasis and schistosomiasis).

There are five overarching research themes within COUNTDOWN, three of which, the mass drug scale-up themes, operate across the four supported countries Liberia, Ghana, Nigeria and Cameroon and are focused on (1) evidence synthesis and Cochrane review, (2) applied social science and health system analysis studies and (3) health economics and financial forecasting. Two other research themes on integrated complementary strategies are specifically undertaken in Ghana and Cameroon and each address disease-specific aspects. For schistosomiasis this includes assessing the cost and impact of biannual praziquantel treatment, expanded access to groups, which are inadequately served (i.e. pregnant women and girls of reproductive age) and implementation of more sensitive diagnostics such as DNA detection methods to better describe the burden of schistosomiasis in those who otherwise do not have egg-patent infections (Stothard et al. 2014b).

A key deficit, which has immediately come to light is a fundamental disconnect and lacking dialogue within the health system linking women's reproductive health and sexual well-being with the prevention and management of female genital schistosomiasis (FGS) (Gyapong et al. 2015). This has a wider significance as there is good evidence that FGS is a risk factor for sexually transmitted viruses such as HIV and HPV (Norseth et al. 2014; Christinet et al. 2015). Within COUNTDOWN, this is starting to be addressed with a comprehensive literature review on FGS (Christinet et al. 2016) and developing a social science research agenda, which will give increased voice to women's experiences of this manifestation of the disease linked with better epidemiological surveillance with modern diagnostic methods (Christinet et al. 2016).

ON LEIPER'S LASTING LEGACY

What would Leiper, the founder of modern helminthology, make of today's situation on 
schistosomiasis? Leiper was no stranger to raising international funds, so he would appreciate the tremendous effort and difficulty needed to mobilize and sustain control interventions by philanthropy. $\mathrm{He}$ would of course be saddened to see the links between schistosomiasis and agriculture decline, largely coincident with the demise of the Commonwealth Bureau of Helminthology but would be heartened to see the Centre for Agriculture and Biosciences International (CABI) and Fournal of Helminthology still vibrant. He would be pleased to see the interdisciplinary nature of COUNTDOWN with an agenda determined in partnership with researchers from endemic countries but would be astonished to learn of the complexity behind the schistosome-snail relationship and that after a century, the world is still far from implementing his simple measures of prevention with total reliance on a single anthelminthic drug. As Leiper once put it to Buckley when asked for his advice, and to close, perhaps it was high time for him "to take another closer look".

\section{ACKNOWLEDGEMENTS}

This manuscript results from a presentation on 8th January 2016 at the University of Glasgow held by the Wellcome Trust Centre for Molecular Parasitology (WTCMP) to celebrate 'Glasgow Encounters with Tropical Diseases'. We thank several colleagues in the WTCMP, Professor Mike Barrett in particular, staff in the archives of the London School of Hygiene and Tropical Medicine, the Natural History Museum and the University of Glasgow for their help and access to materials concerning Robert Leiper's life. In addition, we acknowledge the help of several coworkers in Vector Control Division, Kampala who have assisted in research in Uganda over the years, as well as, general advice and support from colleagues within the COUNTDOWN consortium in particular Mark Taylor, Rachael Thomson, Sally Theobald, Nana KwadwoBiritwum, Mike Osei-Atweneboana, Ifeoma Anagbogu, Anthony Bettee and Karsor Kollie. J. R. S. would like to thank helpful colleagues over the year whilst based in the Natural History Museum, Vaughan Southgate, David Rollinson and David Gibson, especially the late David Brown, for sharing their humorous stories which have given flavour, impetus and desire to write this narrative on schistosomiasis and Leiper's contribution.

\section{FINANCIAL SUPPORT}

This work received no specific grant from any funding agency, commercial or not-for-profit sectors.

\section{DECLARATION OF INTERESTS}

J. R. S. is Director of the COUNTDOWN consortium and together with L. A. T. T. and M. G. received funding from DFID, UK to conduct implementation research on neglected tropical diseases.

\section{REFERENCES}

Adriko, M., Standley, C. J., Tinkitina, B., Mwesigwa, G., Kristensen, T. K., Stothard, J.R. and Kabatereine, N. B. (2013).
Compatibility of Ugandan Schistosoma mansoni isolates with Biomphalaria snail species from Lake Albert and Lake Victoria. Acta Tropica 128, 303-308.

Allen, T. and Parker, M. (2011). The 'Other Diseases' of the millennium development goals: rhetoric and reality of free drug distribution to cure the poor's parasites. Third World Quarterly 32, 91-117.

Andrade, Z. A. (2008). Schistosomiasis and hepatic fibrosis regression. Acta Tropica 108, 79-82.

Atkinson, E. A. (1916). An expedition to the Far East to investigate the spread of trematode diseases, with special reference to Schistosoma japoni$\mathrm{cum}$, and with a note on some protozoa as causes of dysentery. Fournal of the Royal Navy Medical Service 2, 485-490.

Barrett, M. P., Innes, E. A. and Cox, F.E. G. (2015). The Scottish Encounter with Tropical Diseases. University of Glasgow, Glasgow, Scotland. Bustinduy, A. L., Luzinda, K., Mpoya, S., Gothard, P., Stone, N., Wright, S. and Stothard, J. R. (2014). Case Report: Endomyocardial Fibrosis (EMF) in a Ugandan child with advanced hepatosplenic schistosomiasis: coincidence or connection? American fournal of Tropical Medicine and Hygiene 91, 798-800.

Callaway, E. (2016). Dogs thwart effort to eradicate Guinea worm. Nature 529, 10-11.

Campbell, W. C. (1988). Heather and ice: an excursion in historical parasitology. Fournal of Parasitology 74, 2-12.

Campbell, W. C. and Overstreet, R. M. (1994). Historial basis of binomials assigned to helminths collected on Scott's last Antarctic expedition. Fournal of the Helminthological Society of Washington 61, 1-11.

Christinet, V., Calmy, A., Odermatt, P. and O'Brien, D. (2015) Female genital schistosomiasis and human immunodeficiency virus infection: a systematic literature review. Tropical Medicine \& International Health 20, 65-65.

Christinet, V., Lazdins-Helds, J. K., Stothard, J. R. and ReinhardRupp, J. (2016). Female genital schistosomiasis (FGS), will it remain the forgotten gynaecological disease of the future? International fournal for Parasitology 46, 395-404

Cook, G. C. (2007). Tropical Medicine: An Illustrated History of the Pioneers. Academic Press, London.

Cox, F. E. G. (in press). Conributions of Robert Leiper, William Leishman and Muriel Robertson to parasitology in the tropics. Parasitology.

de Moira, A.P., Kabatereine, N. B., Dunne, D. W. and Booth, M. (2011). Understanding ethnic differences in behaviour relating to Schistosoma mansoni re-infection after mass treatment. Fournal of Biosocial Science 43, 185-209.

Dunne, D. W., Vennervald, B. J., Booth, M., Joseph, S., Fitzsimmons, C. M., Cahen, P., Sturrock, R.F., Ouma, J. H., Mwatha, J. K., Kimani, G., Kariuki, H. C., Kazibwe, F., Tukahebwa, E. and Kabatereine, N. B. (2006). Applied and basic research on the epidemiology, morbidity, and immunology of schistosomiasis in fishing communities on Lake Albert, Uganda. Transactions of the Royal Society of Tropical Medicine and Hygiene 100, 216-223.

Farley, J. (1991). Bilharzia: A History of Imperial Tropical Medicine. Cambridge University Press, UK.

Fenwick, A., Webster, J. P., Bosque-Oliva, E., Blair, L., Fleming, F. M., Zhang, Y., Garba, A., Stothard, J. R., Gabrielli, A. F., Clements, A.C.A., Kabatereine, N.B., Toure, S., Dembele, R., Nyandindi, U., Mwansa, J. and Koukounari, A. (2009). The Schistosomiasis Control Initiative (SCI): rationale, development and implementation from 2002-2008. Parasitology 136, 1719-1730.

Fleming, F. M., Fenwick, A., Tukahebwa, E. M., Lubanga, R. G. N., Namwangye, H., Zaramba, S. and Kabatereine, N. B. (2009). Process evaluation of schistosomiasis control in Uganda, 2003 to 2006: perceptions, attitudes and constraints of a national programme. Parasitology 136, 1759-1769. Garnham, P.C.C. (1970). Robert Thomson Leiper, 1881-1969. Biographical Memoirs of Fellows of the Royal Society. Royal Society (Great Britain) 16, 385-404.

Goodwin, L. G. (1996). Schistosomiasis. In The Wellcome Trust Illustrated History of Tropical Diseases (ed. F.E. G. Cox.), pp. 264-273. The Wellcome Trust, London.

Grove, D. I. (1990). A History of Human Helminthology. CAB International, Oxford, UK

Gyapong, M., Marfo, B., Theobold, S., Hawking, K., Page, S., OseiAtweneboanaa, M. and Stothard, J. R. (2015). The double jeopardy of having female genital schistosomiasis in poorly informed and resourced health systems in Ghana. Tropical Medicine ${ }^{\circ}$ International Health 20, 7-7. Hamilton Fairley, N. (1951). Schistosomiasis and some of its problems. Transactions of the Royal Society of Tropical Medicine and Hygiene 45, 279-303. Hotez, P. J. (2013). Forgotten People, Forgotten Diseases: The Neglected Tropical Diseases and their Impact on Global Health and Development. American Society for Microbiology, USA. 
Jordan, P. (2000). From Katayama to the Dakhla Oasis: the beginning of epidemiology and control of bilharzia. Acta Tropica 77, 9-40.

Jorgensen, A., Kristensen, T. K. and Stothard, J. R. (2007). Phylogeny and biogeography of African Biomphalaria (Gastropoda : Planorbidae), with emphasis on endemic species of the great East African lakes. Zoological Fournal of the Linnean Society 151, 337-349.

Kabatereine, N. B., Ariho, C. and Christensen, N. O. (1992). Schistosoma mansoni in Pachwach, Nebbi-District, Uganda, 40 years after Nelson. Tropical Medicine and Parasitology 43, 162-166.

Kabatereine, N. B., OdongoAginya, E. I. and Lakwo, T. L. (1996) Schistosoma mansoni along Lake Albert, Kibale district, western Uganda. East African Medical Fournal 73, 502-504.

Kabatereine, N. B., Brooker, S., Koukounari, A., Kazibwe, F., Tukahebwa, E. M., Fleming, F.M., Zhang, Y., Webster, J.P., Stothard, J. R. and Fenwick, A. (2007). Impact of a national helminth control programme on infection and morbidity in Ugandan school children. Bulletin of the World Health Organization 85, 91-99.

Katz, N. (2008). The discovery of Schistosomiasis mansoni in Brazil. Acta Tropica 108, 69-71.

Leiper, R. T. (1910). Guinea-worm in domesticated animals with a note of its discovery, by Mr C. Grey in a leopard. Fournal of Tropical Medicine and Hygiene 13, 65-66.

Leiper, R. T. and Atkinson, E. A. (1915a). British Antarctic ("Terra Nova") Expedition, 1910. Natural History Report. Parasitic worms with a note on a free-living nematode. British Museum (Natural History); Zoology 2, 19-60

Leiper, R. T. and Atkinson, E. L. (1915b). Observations on the spread of Asiatic schistosomaisis. British Medical fournal 1, 201-192.204.

LeRoux, P.L. (1961). Some problems in Bilharziasis in Africa and the adjoining countries. Fournal of Helminthology 35 (Suppl. S1), 117-126.

Levitz, S., Standley, C. J., Adriko, M., Kabatereine, N. B. and Stothard, J. R. (2013). Environmental epidemiology of intestinal schistosomiasis and genetic diversity of Schistosoma mansoni infections in snails at Bugoigo village, Lake Albert. Acta Tropica 128, 284-291.

Lockyer, A. E., Jones, C. S., Noble, L. R. and Rollinson, D. (2004) Trematodes and snails: an intimate association. Canadian fournal of Zoology 82, 251-269.

Loewenberg, S. (2014). Uganda's struggle with schistosomiasis. Lancet 383, 1707-1708

Manson-Bahr, P. (1961). Robert Thomson Leiper. Supplement in honou of R.T. Leiper on the occasion of his 80th Birthday. Fournal of Helminthology 35, xvi.

Nelson, G. S. (1958). Schistosoma mansoni infection in the West Nile District of Uganda. I. The incidence of $S$. mansoni infection. East African Medical Fournal 35, 311-319.

Nelson, G. S. (1977). A Milestone on the road to discovery of life cycles of human schistosomes. American Fournal of Tropical Medicine and Hygiene 26, 1093-1100.

Nelson, G. S. (1990). Microepidemiology, the key to the control of parastic infections. Transactions of the Royal Society of Tropical Medicine and Hygiene 84, 3-13.

Norseth, H. M., Ndhlovu, P.D., Kleppa, E., Randrianasolo, B.S. Jourdan, P. M., Roald, B., Holmen, S. D., Gundersen, S. G., Bagratee, J., Onsrud, M. and Kjetland, E. F. (2014). The colposcopic atlas of schistosomiasis in the lower female genital tract based on studies in Malawi, Zimbabwe, Madagascar and South Africa. Plos Neglected Tropical Diseases 8. doi: 10.1371/journal.pntd.0003229.

Ongom, V. L. and Bradley, D. J. (1972). Epidemiology and consequences of Schistosoma mansoni infection in West Nile, Uganda. 1. Field studies of a community in Panyagoro. Transactions of the Royal Society of Tropical Medicine and Hygiene 66, 835-851.

Parker, M. and Allen, T. (2011). Does mass drug administration for the integrated treatment of neglected tropical diseases really work? Assessing evidence for the control of schistosomiasis and soil-transmitted helminth in Uganda. Health Research Policy and Systems 9. doi: 10.1186/14784505-9-3.

Parker, M., Allen, T. and Hastings, J. (2008). Resisting control of neglected tropical diseases: dilemmas in the mass treatment of schistosomiasis and soil-transmitted helminths in north-west Uganda. Fournal of Biosocial Science 40, 161-181.

Rollinson, D. (2009). A wake up call for urinary schistosomiasis: reconciling research effort with public health importance. Parasitology 136, 1593 1610 .

Rollinson, D., Knopp, S., Levitz, S., Stothard, J. R., Tchuente, L.-A. T., Garba, A., Mohammed, K. A., Schur, N., Person, B., Colley, D. G. and Utzinger, J. (2013). Time to set the agenda for schistosomiasis elimination. Acta Tropica 128, 423-440.

Rowel, C., Fred, B., Betson, M., Sousa-Figueiredo, J. C., Kabatereine, N. B. and Stothard, J. R. (2015). Environmental epidemiology of intestinal schistosomiasis in Uganda: population dynamics of Biomphalaria (Gastropoda: Planorbidae) in Lake Albert and Lake Victoria with observations on natural infections with digenetic trematodes. Biomed Research International. doi: 10.1155/2015/717261.

Savioli, L., Fenwick, A., Rollinson, D., Albonico, M. and Ame, S. M. (2015). An achievable goal: control and elimination of schistosomiasis. Lancet 386, 739-739.

Seto, E.Y.W., Sousa-Figueiredo, J. C., Betson, M., Byalero, C., Kabatereine, N. B. and Stothard, J. R. (2012). Patterns of intestinal schistosomiasis among mothers and young children from Lake Albert, Uganda: water contact and social networks inferred from wearable global positioning system dataloggers. Geospatial Health 7, 1-13.

Southgate, V.R., Rollinson, D., Tchuente, L. A. T. and Hagan, P. (2005). Towards control of schistosomiasis in sub-Saharan Africa. Fournal of Helminthology 79, 181-185.

Stothard, J. R., Sousa-Figueiredo, J. C., Betson, M., Green, H. K., Seto, E.Y.W., Garba, A., Sacko, M., Mutapi, F., Nery, S. V. Amin, M. A., Mutumba-Nakalembe, M., Navaratnam, A., Fenwick, A., Kabatereine, N. B., Gabrielli, A. F. and Montresor, A. (2011). Closing the praziquantel treatment gap: new steps in epidemiological monitoring and control of schistosomiasis in African infants and preschool-aged children. Parasitology 138, 1593-1606.

Stothard, J. R., Sousa-Figueiredo, J. C., Betson, M., Bustinduy, A. and Reinhard-Rupp, J. (2013). Schistosomiasis in African infants and preschool children: let them now be treated! Trends in Parasitology 29, 197-205. Stothard, J. R., Bustinduy, A. and Montresor, A. (2014a). Preventive chemotherapy for schistosomiasis and soil-transmitted helminthiasis by cotreatment with praziquantel and albendazole. Clinical Investigation 4, 163-176.

Stothard, J. R., Stanton, M. C., Bustinduy, A. L., Sousa-Figueiredo, J. C., Van Dam, G. J., Betson, M., Waterhouse, D., Ward, S., Allan, F., Hassan, A. A., Al-Helal, M. A., Memish, Z. A. and Rollinson, D. (2014b). Diagnostics for schistosomiasis in Africa and Arabia: a review of present options in control and future needs for elimination. Parasitology 141, 1947-1961.

Tanaka, H. and Tsuji, M. (1997). From discovery to eradication of schistosomiasis in Japan: 1847-1996. International Fournal for Parasitology 27, $1465-1480$.

WHO (2013). Schistosomiasis: Progress report 2001-2011 and Strategic Plan 2012-2020. WHO, Geneva, Switzerland.

WHO (2015). Investing to Overcome the Global Impact of Tropical Diseases Third Report on Nelgected Tropical Diseases 2015. WHO, Geneva, Switzerland.

Willmott, S. (1981). Leiper, Robert Thomson, 1881-1969 - Centenary biographical note. International fournal for Parasitology 11, 423-424. Zou, L. and Ruan, S. G. (2015). Schistosomiasis transmission and control in China. Acta Tropica 143, 51-57. 